\title{
The work of health auxiliaries in social services and the implementation of a new approach to intervene with clients with dementia
}

\author{
Marie-Michèle Lord ${ }^{1}$, Pierre-Yves Therriault ${ }^{2}$, Lyne Desrosiers ${ }^{3}$, Ginette Aubin ${ }^{4}$ \\ ${ }^{\prime}$ (Ph.D. candidate in biomedical science, Université du Québec à Trois-Rivières, Canada) \\ ${ }^{2,3,4}$ (Professor, Department of Occupational Therapy, Université du Québec à Trois-Rivières, Canada)
}

\begin{abstract}
The aging of the population leads to an increase in the needs for seniors who want to stay at home. In the home support business line, programs are deployed, new methods for dealing with clients are implemented, and technologies are increasingly being used to improve the services offered. Although several studies focus on the factors that may have an impact on the work and health of healthcare and social service providers, few focus on home support aides. Even fewers studies talk about the impact of innovation on the work and health of these workers. The purpose of this article is to present the results of a study carried out among healthcare and social services workers in a region of Quebec, in Canada. The analysis of the results allows us to draw a picture of the sources of satisfaction and suffering associated with the practice of this profession, as well as the strategies used by the participants to cope with the suffering. Moreover, the analysis of the results leads to a reflection on innovation in this sector of activity.
\end{abstract}

Keywords - Health auxiliaries. Innovation. Health at work. Home support.

Home support for the aging population

\section{INTRODUCTION}

Place where a person resides, place of belonging and object of strong emotional investment, the domicile is a constituent of the identity [1]. People develop memories in their homes, build intimacy and must be able to feel safe there [2]. This vision of the domicile, which goes well beyond the simple place of refuge, is dominant in social practices [3]. It has led to the development of a culture of home care, where it is considered preferable to allow the older person to stay at home and in their community rather than inciting them to resort to an accommodation institution [4]

Staying at home is not easy as of a certain age. Many types of problems can limit the daily activities of the elderly. Thus, long-term care or continuing care must be provided to enable dependent persons to continue living at home while receiving assistance [5]. In Canada, home care is defined by Health Canada as a range of services that enable clients with disabilities to live in their own homes, often with the effect of preventing, delaying or replacing acute care or long-term care.

These services are increasingly being sought, partly because of the aging of the population that is occurring in Canada and in several industrialized countries. This situation is likely to continue in the coming years, as the improvement in life expectancy is constantly leading to a steady increase in the proportion of people aged 65 and over in the population. While in 1991, 30\% of seniors aged 85 and over had a need for personal assistance, this percentage was $59.7 \%$ in 2009 [6].

Services offered at home to an aging population are varied and range from treatment and health care services to personal support services. Services in support of daily and domestic activities are among the most popular [7]. For example, in 2003, 10\% of Canadians aged 75 and older needed personal care assistance, while $25 \%$ needed help with household chores [8]. The majority of the services provided at home are moreover filled by support workers, such as personal support workers and personal care workers [6].

\section{Transformations in the Home Care Sector}

In Canada, home care programs have evolved dramatically over the past 40 years. Prior to 1970, these programs focused on acute patient care at home and were mainly organized by local community organizations. In the late 1980s, home care programs were systematized and were gradually taken up by the state, but support services were provided only to certain populations, including the frail elderly. In the early 1990s, all provinces in Canada offered home care services to a wider range of clients.

Then, in the late 1990s, the growing need for health care and social services to support the needs of the aging population resulted in a significant increase in public health expenses in Canada [9]. In an effort to 
rationalize costs, the front-line of public sector healthcare facilities were strongly affected by a reorganization that favored the decentralization of health care. Federal transfers to provinces and territories have resulted in the development of extended health care services, including ambulatory care and home care, as well as other longterm care such as continuing institutional care [10]. This reorganization resulted in a shift of responsibility from the state to other social actors, including the family, the community sector and the private sector. These organizational changes in care have resulted in changing roles for tens of thousands of relatives of elderly people with dementia who suddenly found themselves in a caregiving position.

To facilitate the maintenance of seniors at home and to reduce the new burden of caregivers, the programming of activities aimed at optimizing functional and psychosocial autonomy has undergone various developments [11]. During the 2000s, measures were developed and implemented by different organizations to optimize the services offered to this population. The latter were characterized mainly by the implementation of new programs and the increasing use of assistive technology, for security and surveillance functions [12].

More specifically, home care services for elderly people with cognitive problems have developed significantly in the last few years. Moving from a dominant functionalist paradigm, where the primacy is given to the reduction of disabilities, several studies now advocate the consideration of positive psychology as a basis for intervention among elderly people with dementia. Strengthening the potential of individuals becomes central to the process. This is a true paradigm shift [13], which is part of a positive psychology perspective, by increasing the potential of individuals [14] and the positive aspects of the caregiver role [15].

\section{Health of workers in the home support sector}

Difficult working conditions experienced by home care workers have been extensively studied over the years to determine the health risks associated with their jobs. Workers in this sector are at risk of developing health problems related to the practice of their profession, particularly in regard to their psychological health. In $2015,43.9 \%$ of the costs incurred in salary insurance for these workers were associated with mental health problems [11]. A review of the literature identified five major risk factors for the health of these workers. These factors are: (1) high physical demands [16;17], (2) client assaults that put their mental and physical health at risk [18], (3) ethical suffering linked to a gap between the prescribed organization and the actual organization of tasks [19], (4) low social support and poor decision-making latitude [20], and (5) strong emotional demands and low recognition at work [21].

Organizational transformations in the health sector, as noted by efficiency practices and the use of modern technologies, have been documented in a few studies carried out mainly with nurses (see, for example [22]; [23]; [24]). Although these studies reveal that the reorganization of the health network has resulted in a higher level of psychological distress among the workers, few studies document the impact of such reorganization on the work and health of workers. When discussing changes and innovations in the workplace, the scientific literature focuses on management practices, administrative strategies, the quality of services rendered and the satisfaction of the clientele being served. The impacts on the physical and mental health of staff undergoing organizational changes are much less known and explored [22]. This is what Simpson, Siguaw and Enz [25] call the positive bias associated with innovation. It refers to the lack of an objective view of the effects of innovation in the scientific literature, where innovation in the workplace is generally presumed desirable, without really questioning its results on work activity and its positive or negative effects on the workers' health.

\section{Objectives of the research}

As outlined in the introduction, the population is aging and many seniors require assistance in carrying out their daily and domestic activities. Home care services help to support the aging person and his or her loved ones for safe home support. These services have changed greatly over the years and innovation is very present in this sector of activity. Organizational transformations have an impact on work activity and may even have an impact on the workers' health [26]. Yet little evidence exists about the impact of innovation on the work and health of workers in the home care sector. In this context, this article aims to present the results of a study aimed at exploring the impact of an innovation on the subjective relationship maintained by home support workers with their work activity. This paper focuses on the sources of satisfaction and suffering experienced by health and social service workers working in a health unit in a Quebec sociosanttory region, as well as the strategies put in place by the latter to counter suffering at work.

\section{METHODOLOGY}

\section{Research Design and conceptual framework}

The study presented is of a qualitative nature, based on group interviews. The methodology is part of the comprehensive interpretation of qualitative research and is based on the principles of anchored theorization 
[27], especially from the point of view of data processing. The aim is to examine work through the workers' voices, without aiming at completeness [28].

The conceptual framework used is work psychodynamics. The latter assumes that in the organization of work, between prescribed work and actual work, dynamics are played where people are both determined and constrained by structural elements while being free and active. The analysis of these dynamics, deployed consciously or not by the workers, gives an understanding of the subjective experience of the latter in relation to their work activities. Briefly, the basic postulates of work psychodynamics indicate that work is a place of selfproduction for the worker who decides to engage in it [29]. It allows, in the experience of surmountable sufferings with the aid of ingenuity and creativity, to live satisfaction in carrying out work activity. When challenges can't be overcome, because they are too important or the worker does not have the opportunity to use his or her abilities, then potentially harmful suffering occurs [30]. To cope with this, the worker, either individually or with his co-workers, will develop strategies that will enable him to continue working despite the suffering elements of everyday life. Although they are protective, defensive strategies can be harmful in the long run, since they don't really allow workers to escape from suffering, but rather make it more acceptable for a while [31]. The discovery of suffering, but most of all the awareness of defensive strategies and their adjustment as necessary, is part of a move towards improving mental health in the workplace.

\section{Data collection}

Participants were recruited from a health care facility that provides home care to an aging population and that has recently implemented a new approach for workers working with seniors with dementia. Several types of workers participated in the research: volunteers in support of people with Alzheimer's disease and their families; social workers in home support; home support workers performing in a private services cooperative, health auxiliaries in social services working in a public health service.

In accordance with the preferred method in work psychodynamics, groups have been formed to bring together workers of the same function in a same organization structure. According to this perspective, the study aims to create an environment facilitating the emergence of the most authentic discussions possible on the part of the workers based on concrete experiences of work. Therefore, the investigation group is made of workers holding the same function and belonging to the same hierarchy [30]. For researchers, the worker, perceived as the bearer and producer of meaning, remains the better person to express and understand how they experience their relationship to work, sources of satisfaction and sources of difficulty [32].

The results of the group of health auxiliaries in social services are those presented in this article. The study was conducted in 2016, in four separate meetings. Each meeting, of three hours each, favored free speech of workers on their work activity by using open questions. More specifically, the first two meetings were aimed at exploring the sources of satisfaction and suffering in the work of health auxiliaries in social services as experienced by the participants, as well as the means put in place to counter the difficult elements in work. After a first analysis of the results by the researchers, the understanding of the situation was explained to the group in the third meeting. Participants were encouraged to further develop their work, to clarify the impact of in novation on their work activity and their subjective relationship with it. Finally, the objective of the fourth meeting was the presentation of a report on the intercomprehension of the work situation, to realize a final step of refinement of the understanding. A total of six auxiliaries participated in the study. All participants were women.

\section{Innovation studied}

At the time of the study, a new program to intervene with clients with dementia had just been implemented in the studied workplace. This program is called Approche de rehaussement de la qualité de vie des aidants et de leurs proches atteints de démence (ARQVAP). It is based on new types of care for this kind of health problem, which aim the emotional needs and seek to provide pleasant moments for the aging person rather than only addressing physiological needs [14].

As part of the implementation of this approach, auxiliaries received half-day training on the principles of ARQVAP. Concretely, the approach involves continuing to carry out the same tasks as before, but rather than emphasizing the efficiency of care, workers must emphasize having an enjoyable experience with the client through care. To do this, the auxiliaries can use different tools placed at their disposal, such as charts that identify significant activities for clients, leisure objects and teaching cards for caregivers. Unlike the other stakeholder's groups interviewed in the study, health auxiliaries in social services did not have access to mentoring to track the use of ARQVAP with clients in the field.

\footnotetext{
${ }^{1}$ Which can be translated by: Approach to Enhancing the Quality of Life of Caregivers and their Loved one with a Memory Disorder. 


\section{RESULTS}

The results section is divided into five parts. The first describes the work of the health auxiliaries in social services as detailed by the participants. The next two focus on sources of satisfaction and suffering in the workplace. The defensive strategies employed by the auxiliaries are then detailed in the fourth part and finally, the impact of innovation as perceived by the participants is presented.

\section{The work of the health auxiliaries in social services}

The home support service, which is aimed at seniors or those with a loss of autonomy, has been set up to help them stay at home. According to the participants, between $70 \%$ and $80 \%$ of the clientele are elderly people with a dementia problem. In the home support service, about fifteen positions are associated with the "health auxiliaries in social services" category. Although the auxiliary group meets for one hour on the premises of the home support service on a weekly basis, they perform individualy their various tasks mostly alone in their client's homes.

The facility provides life support services associated with assistance to the general person, such as occasional sunrise or bedtime assistance, hygiene care, meal preparation and supervision during medication. Following the tranformation of law environment ${ }^{2}$, it appears that the task of auxiliaries has evolved towards the application of nursing non-invasive type delegated activities. These activities may include changing a dry dressing, doing rectal cleansing, cleaning a stoma. According to the participants, between $90 \%$ and $95 \%$ activities carried out by the auxiliary refer to hygiene care.

In general, the tasks to be performed vary according to the assignment schedule. This schedule, called "route" by the participants, is prepared by the coordination of the home support program. The road is available, physically or virtually, one week in advance. The time reserved for a service is about 50 minutes per assignation. A typical day includes five or six assignations, sometimes seven. Time for travel from one place to another is also planned. An auxiliary can visit the same user several times a week. The qualities recognized by the participants to seriously carry out the profession of auxiliary in health and social services are the following: autonomy, generosity, judgment, resourcefulness, versatility, capacity of adaptation.

\section{Sources of satisfaction in the work}

The primary source of satisfaction, which is essential for the participants, is the one associated with establishing the helping relationship. More specifically, to build a supportive relationship that is respectful of the client's needs, his desires, but also his limits and which is focused on well-being. For the participants, it is the very basis of their understanding or apprehension of their work. Respecting the client and humanizing the care and services provided is fundamental and it is a satisfaction for them to be able to do so in their work, since the working environment in which they operate allows them to do so. As a participant explains: "At home, we act with respect. We have a lot of respect for the clients, we have a lot of humanity. We listen to them, and we go at their own pace, without rushing, without violence. That's what we love about our work, helping our client. "3

To be able to keep up with their clients, auxiliaries must be able to use their judgment and adapt their interventions. The organization of work offers them this possibility and they have power in their work. This notion of power is also fundamental in the work of the participants and corresponds to the second source of satisfaction at work: power on the act posed. The auxiliaries can thus act in accordance with their owns values; what they do corresponds to who they. This power on the act is intimately linked to a real autonomy felt at work, where a margin of maneuver is possible. The health auxiliaries in social services have the real power to modulate their intervention.

The third source of satisfaction is recognition. First, the recognition of clients and their loved ones on the quality of care and tasks performed at home: "The recognition of customers is very important. They are happy to see us, they say thank you. Sometimes it's only a smile that means thank you, I appreciate your work, and it's very rewarding ". Second, recognition from the employer, the team leader and from other professionals is essential. This recognition is reflected in the confidence towards the auxiliary's judgment and in the credibility of their interventions. The auxiliary's judgment is respected and the latter has access to discussions with other professionals as needed: "our intelligence is recognized" "Here we feel that we are believed, we are taken seriously", "We are not alone in front of the client's difficulties, we have a team. That's what I like about home support, it's very easy access to the team, to resources. We are taken seriously ".

\footnotetext{
2 The Act to amend the Professional Code and other legislative provisions in the field of health is a bill that contains provisions that will allow non-professionals, in certain circumstances or in certain well-identified environments, to carry out certain activities to better meet the needs of the population.

${ }^{3}$ In the text, the sentences in parentheses are taken from the verbatim obtained during the group interviews with the participants. Since the meetings were held in French, it is a free translation of the workers' statements, which is as faithful as possible.
} 


\section{Sources of suffering in the work}

The first source of suffering named by the participants, and the most important one, is the encroachment of work on privacy. Several auxiliaries indicated that during their career they had to make a lot of sacrifices, for example because of the work schedule (evenings, weekends, work on public holidays). Regrets are now expressed: "I often say that what I do is the most beautiful job in the world, but at the same time I say that if I had to do it again, I would not do it again", " the most hurtful is how many family vacations I sacrificed. My children reproach me for my absence when they were young. Now they are too old to want to build a close relationship with me. I have the repercussions of that today and I regret. "

Also, working in helping relationship involves a lot of situations that forces one to witness the suffering of the other, which leaves traces. A feeling of sadness, but also of helplessness when confronted with the limitations of the intervention and the resources available, constitutes a second source of suffering for the participants. Although they are aware of the limitations of their actions and the importance of maintaining this limit, residues from hard cases remain difficult to bear, as reported here: "Sometimes the home is unhealthy and we see a lot of misery. It's difficult emotionally. For example, I often see people who can't eat, are poor and hungry. It's hard. ". Another participant added: " Sometimes, we think of our clients after work, especially if we are facing a person who has many needs but the services that we can offert them are limited. ".

Then, as part of their work, auxiliaries enter the privacy of their clients. A discomfort can then be felt. The latter is not related to the intimacy of the body, but rather to the intimacy of the place. This third suffering is present when the participants feel that they are entering the personal space of the clients. For example, when they must go into a client's house by themselves after ringing repeatedly, when they must find clothes in the drawers or find hygiene products in the cupboards. In this sense, a paradox is raised; the auxiliaries expressed their discomfort at the fact of entering the intimacy of the physical space of the clients, while they feel no embarrassment to share the physical intimacy of these people.

Boredom, linked to the routine nature of work, is another source of suffering identified by the participants. Carrying out the same route for a long period of time involves meeting the same clients for a long time and hearing the same stories repeatedly: "For some clients, when I enter their house, I can say in advance what they will tell me, almost word for word. They don't remember what they told me last time because of their dementia. I understand that it is not their fault, that these people can't invent new stories, but that can become heavy."

Loneliness is also a source of suffering, especially since auxiliaries work very little with their colleagues. Despite a weekly team meeting, opportunities to share experiences, good moves, and mutual appreciation are extremely rare in the current organization of work: "Basically, we are a group of individuals "," Meetings are not a place for exchanges. We're running, we're dizzy. Sometimes there'splenty of new clients to discuss, there's hardly any time left to talk. " Attempts to set up peer-to-peer mechanisms are not very effective, as the participant said: "The employer planned a moment at the end of the meetings to highlight the good work of another one of our colleagues. For example, an auxiliary can say that one of her colleagues did well in the week. But it is done in speed at the end of the meeting, everyone is already up and we say it shouting ".

Finally, auxiliaries are aware that their role is poorly understood and little socially recognized. Although they can be proud of their work and are conscious of bringing something essential to society, this lack of recognition and the judgment of others may be suffering, as one participant explained: " Our job is not a highly socially valued job. I often hear others say; it's disgusting, you always have your hands in the poo and your job is to wash the buttocks...I realize that people don't know and they don't understand that what we do is much more than that "

\section{Defensive strategies used to deal with suffering}

Health auxiliairies in social services use defensive strategies, which are devices put in place by workers to contain anxiety and suffering.

A first strategy shared by the participants is "Putting their limits". The latter is defined according to two operating modes. The first is to tell the supervisor that it is impossible to continue working with a client. Auxiliaries use this strategy when faced with situations of danger, insalubrity or inappropriate behavior of a client. The norms regarding the contexts where this strategy can become operationalized appeared more or less explicit. For each situation, it is up to the superior to determine if the limit has been crossed and to determine if the employee can be relieved of his task. Nevertheless, most of the time, this defensive strategy unfolds without constraint, with the assent of the organization, and the recourse to it does not in fact appear to be disputed. This strategy offers them a bonus recognition of the accuracy? of their judgment which they say is never questioned. The auxiliary will, in most cases, be allowed to cease his activities with the client without any doubting of his statements and without any blame or sanction: "There is a situation where I was afraid, so I shortened my care and I talked with my manager. He believed me. We are supported". 
The second mode of operation of this strategy is not to put limits on its commitment to a client, but rather to limit the extent of tasks performed with him. Auxiliaries must use this strategy when they are confronted with clients who ask them to perform tasks that are not covered by the service plan. For example, a shower may be asked rather than bed-bathing. Although some participants manage to set their limits, for others this strategy becomes ineffective when they witness the suffering of clients. To tolerate painful emotions when they find themselves exposed to situations of misery, these auxiliaries will use a strategy identified as "Helping in secret". This involves performing an "out-of-bounds" task in an area that goes beyond the service plan but with minimal risk to their health and safety.

To cope with such suffering as helplessness in situations of extreme poverty, or the boredom caused by the repetition of the same gestures, the same exchanges with a client, certain auxiliaries claim to have to "Become heartless". This strategy consists in cutting off psychologically painful affects and in some way inhibiting humanity, as this participant explains: "We disconnects from emotions, we no longer feel anything. That allows us to continue to do our work", as well as the comments made by this one: "I tell myself that I am becoming heartless. I can't let myself be invaded by emotions all the time, it would not be functional. It's the experience that makes me put a barrier more easily ".

As mentioned earlier, a paradox associated with the concept of intimacy is present in the perception that auxiliaries have of their work. Indeed, the latter involves assisting people in very intimate activities such as hygiène care of the genitals. But it is not these tasks that make the auxiliaries uncomfortable. It is rather the fact of being at the client's house, in his personal belongings. This suggests mechanisms of displacement, from the intimacy of the client's body to the intimacy of his environment.

\section{The impact of innovation for health auxiliaries in social services}

For the participants, the implementation of ARQVAP had no impact on the work. Indeed, they consider that although the foundations of the approach are consistent with the vision they have of their work, it does not bring novelty to the interventions. Moreover, they add that the arrival of ARQVAP did not bring any change in their tasks, as they mention: "We do not need the approach to live pleasant moments with our customers, it's already part of our approach, our tricks of the job. We did it before, we do it now. " Thus, majority of participants indicated that they did not use ARQVAP it their practice.

Some auxiliaries indicate that although the concepts underlying the approach are very integrated with their work, the proposed tools can't be used in the organizational context. Indeed, working at home is not conducive to the use of tools proposed in ARQVAP, due to a lack of time and since frequent travel poses a barrier. Auxiliaries prefer to use what is already present in their clients' homes to establish the relationship (for example photo album, music).

Finally, the participants emphasized that all of them have several years of experience at work and believe that the approach could be favorable for the novices, to equip them to work in accordance with the values of the profession: " Training on the approach could be useful for young people who are starting out. We have been trying to transmit these principles for a long time when we train the new and young people who arrive. "

\section{DISCUSSION}

The work of health auxiliaries in social services involves a lot of suffering, mainly related to the overflow of the profession on the privacy and the realization of tasks with a very vulnerable clientele. This relationship implies to witness situations of precariousness for which it is not always possible to act. These results are not surprising since the literature on these careers regularly reports the distress of these professionals linked to the constant experience of pain and fragility of the client (see, for example, [33]; [34]). Similarly, the lack of social recognition of this job is not a new fact either. Still predominantly female, auxiliary jobs pose the problem of the naturalization of so-called feminine qualities, whose experience continues to be invisible [35].

What is quite new, first, from the analysis of the results obtained, is that the sources of satisfaction expressed by the participants are usually more a source of suffering in several studies of health care providers. In particular, the ability to act in accordance with their personal and professional values, and the recognition received by clients and the organization of work. It is thus possible to note that certain labor organizations offer conditions for the exercise of the profession that create favorable conditions for its realization. Among other things, recognition at work is fundamental to health at work [31] and passes through two types of judgment on the work done: utility essentially uttered by others on the vertical line (eg hierarchical superiors, subordinates, helpers) and the judgment of beauty, placed on the horizontal line by the peers of the same function. These forms of recognition constitute a fundamental condition for the development of self-esteem, which is essential to the construction of identity [29] and the auxiliaries encountered seem to have access to both types in the exercise of their work, although obtaining the judgment of beauty is more difficult given the aspect of loneliness in the work. Although the team meeting is one of the places to ask beauty judgment, the timing is often expeditious. This is often the case when it comes to peer recognition in organizations. An earlier study 
suggested that measures to support the work collectivity proved to be an avenue to promote the psychic health of family workers [36]. In the case studied, the means taken by the organization to do so are not sufficient.

Another aspect highlighted in the study that was carried out is the paradox associated with intimacy. The defensive strategy, which consists in giving an intimate character to objects and places rather than the bodies on which the care is provided, has, to our knowledge, been little discussed in the literature. Usually, the strategies used to deal with the disgust of the care are of the order of idealization of the cared for, as being "a beautiful patient" [37]. A symbolic reconfiguration that reorders the world according to what counts to maintain a helping relationship normally lingers on magnifying the diseased body or reifying the body to be healed. For the participants, the reconfiguration rather takes place through a humanization of the objects, which is perhaps psychically less expensive to do.

\section{The relationship with innovation}

Implementing innovation in the health and social services sector is not easy. Indeed, studies show that little innovation passes the stage of experimentation and that innovative projects tend to be abandoned rapidly or to be used locally [38]. The analysis of the results of this study goes in this same direction, to the extent that even if the program is considered already part of the work, a tendency of the auxiliaries is not to integrate the material and tools available in ARQVAP in their practices. The reasons for this decision are partly due to a lack of coherence between the practical requirements of the use of the tools and the context of care delivery, which is usually a factor of importance already documented in various studies [39].

Moreover, it seems that the program implemented in the workplace, which is considered an innovation by the organization, is not considered as such by the participants. This perception appears to negatively tint their desire to adhere to the proposed approach. It would have been possible to expect that an innovation that fits with workers' practices would be welcomed by the latter. Yet, in this case, innovation is considered trivial as it dictates to the auxiliaries to act as they already do. Deemed perhaps good for novice workers, this is an unnecessary prescription for them. It is possible to question what underlies this perception. Does this perception come from the fact that some so-called innovative programs do not bring real added value and are rather implanted to look good? Considering the idealization of innovation in modern society and the imperative given to companies to adhere to this culture, this would hardly be surprising. Or is this perception more linked to how innovation has been presented, proposed and taught to auxiliaries? It is pertinent here to recall that only half-day training was used as an integration measure, while for other groups of workers, regular mentoring sessions provided a link between the approach and practice on the ground. If this is the case, proposing an innovation that is coherent with the work does not seem sufficient for the workers to adhere to it. It may be appropriate to emphasize the added value that the proposed innovation brings to work and to ensure its applicability in the work context.

\section{CONCLUSION}

This study has shed light on the little documented and often poorly understood work of family support workers. Although this study was carried out with a small number of auxiliaries, it was found that, despite certain inherent sufferings of this job, auxiliaries can derive great satisfaction from the performance of their duties, especially when they work in a context that promotes trust and offers recognition. It will be interesting to compare these results with those obtained by family auxiliaries working in a care cooperative to better understand the impact of organizational factors on this work. In terms of innovation, given that the participants felt that ARQVAP had no impact on their tasks, it was not possible to make connections between innovation and changes in the work. On the other hand, the analysis of the results led to a new track, towards the start of reflection on the idea of innovation itself and its marketing in company. Among other things, it would be interesting to see how innovation is integrated into business. Is it always prescribed and imposed by the organization of work, or is there in some cases real support for workers? Such a posture would be favorable for the health of workers.

\section{REFERENCES}

[1] E Djaoui, Approches de la culture du domicile, Gérontologie et société, 1, 2011, 77-90.

[2] A Ferrari, Habitat et espace psychique chez le sujet âgé, Le Journal des psychologues, 7, 2007, 47-50.

[3] B Ennuyer, Repenser le maintien à domicile : enjeux, acteurs, organisation (Paris : Dunod, 2006)

[4] E Bourdi, C. Breton and S. Plançon, Vieillir et rester à domicile, Soins gérontologie, 20, 1991, 36-39.

[5] R Wilkins and J. Chen, Seniors' needs for health-related personal assistance, Health Reports, 10(1), 1998, 39-50.

[6] Canadian Institute for health information, Health Care in Canada, 2011: A Focus on Seniors and Aging.

[7] K Chevreul, L. Com-Ruelle, F. Midy, and V. Paris, Le developpment des services de soins hospitaliers à domicile (Paris: IRDES, 20075). 
[8] Statistiques Canada (2006). Le recensement 2006: portrait de la population canadienne selon l'âge et le sexe (97-551-XWF).

[9] A Constant, S. Petersen, C. D. Mallory and J. Major, Research synthesis on cost drivers in the health sector and proposed policy options. Rapport de la Fondation canadienne de la recherche sur les services de santé sur les facteurs de coût et l'efficacité du système de santé. 2011, Ottawa, Fondation canadienne de la recherche sur les services de santé.

[10] I. Gagnon, H. David, E. Cloutier, F. Ouellet, E. Ledoux, M. Bourdouxhe and C. Teiger, Organisation du travail et développement de stratégies protectrices: cas d'auxiliaires sociales et familiales de services publics de maintien à domicile. Gérontologie et société, 4, 2003, 131-148.

[11] MSSS (2015). Gestion de la présence au travail. Assurance salaire 2014.

[12] B Bouchard, Recherche sur les technologies d'assistance pour le maintien à domicile des personnes atteintes d'Alzheimer. Journée de la recherche du FRQNT, Sherbrooke, Qc, 2013.

[13] C. Carruthers and C.D. Hood, Building a life of meaning through therapeutic recreation: The leisure and well-being model, part I, Therapeutic Recreation Journal, 41(4), 2007, 276-297.

[14] H Carbonneau, L. Fontaine, and M.A. Lussier, Approche loisir pour la clientèle avec déficits cognitifs graves: Quand la mémoire fuit, accompagner dans la tendresse (Sherbrooke: Institut universitaire de gériatrie de Sherbrooke, 2004).

[15] H Carbonneau, C.D. Caron and J. Desrosiers, Effects of an adapted leisure education program as a means of support for caregivers of people with dementia, Archives of gerontology and geriatrics, 53(1), 2010, 31-39.

[16] S Bédard, Lésions professionnelles en CHSLD, Objectif Prévention, 26(2), 2013, 30-31.

[17] M Bigaouette, Prévenir les lésions professionnelles et améliorer la qualité du milieu de vie, Objectif Prévention, 34(2), 2011, 10-12.

[18] M.S. Lachs, T. Rosen, J.A. Teresi, J.P. Eimicke, M. Ramirez, P. Silver and K. Pillemer, Verbal and physical aggression directed at nursing home staff by residents, Journal of general internal medicine, 28(5), 2013, 660-667.

[19] F Aubry and Y. Couturier, Regard sur une formation destinée aux préposés aux bénéficiaires au Québec. Gestion de contradictions organisationnelles et souffrance éthique, Travailler, 31(1), 2014, 169-192.

[20] R Bourbonnais, N. Gauthier, M. Vézina, C. Viens, P. Durand, C. Brisson, M. Alderson, P. Bégin, and J.P. Ouellet, Une intervention en centres d'hébergement et de soins de longue durée visant à réduire les problèmes de santé mentale liés au travail, Perspectives interdisciplinaires sur le travail et la santé, 7(2), 2005, 1-35.

[21] F Aubry, L'innovation en milieu hypernormalisé. Le cas des préposés aux bénéficiaires dans les organisations gériatriques au Québec, Cahiers de recherche sociologique, 53, 2012, 11-32.

[22] R Bourbonnais, Les impacts positifs et négatifs de la transformation du réseau de la santé sur la vie professionnelle, la vie familiale et la santé des infirmières et des infirmiers de l'agglomération de Québec: rapport de recherche soumis au Conseil québécois de la recherche sociale, CQRS (Québec: Presse Université Laval, 2000)

[23] G Cummings, L. Hayduk and C. Estabrooks, Mitigating the impact of hospital restructuring on nurses: the responsibility of emotionally intelligent leadership, Nursing research, 54(1), 2005, 2-12.

[24] A McVicar, Workplace stress in nursing: a literature review, Journal of advanced nursing, 44(6), 2003, 633-642.

[25] P.M. Simpson, J.A. Siguaw and C.A. Enz, Innovation orientation outcomes: The good and the bad, Journal of Business Research, 59(10), 2006, 1133-1141.

[26] P.Y. Therriault, J. Rhéaume and U. Streit, Identité de métier en péril chez des machinistes suite à des transforma-tions organisationnelles et technologiques, Le Travail Humain, 67, 2004, 333-357.

[27] B.G. Glaser and A.L. Strauss, The Discovery of Grounded Theory : Strategies for Qualitative Research (Chicago : Aldine Pub. Co, 1967)

[28] A Honneth, La lutte pour la reconnaissance (Paris: CERF, 2000)

[29] C Dejours, Travail et usure mentale - De la psychopathologie à la psychodynamique du travail (Paris : Bayard, 2000)

[30] C Dejours, Travail vivant 2 : Travail et émancipation (Paris : Petite bibliothèque Payot, 2013)

[31] M Alderson, M. Saint-Jean, J. Rhéaume and I. Ruelland, Impasses dans le travail d'infirmières en Centres d'hébergement de se soins de longue durée soumis à des changements organisationnels significatifs, Aporia, 3(4), 2011, 30-46.

[32] P Canouï, La souffrance des soignants: un risque humain, des enjeux éthiques, InfoKara, 18(2), 2003, 101-104. 
[33] S Fanello, B. Ripault, V. Heuze, Y. Roquelaure, S. Verrier, B.A. Kandouci and D. Penneau-Fontbonne, Souffrance psychique liée au travail: étude réalisée chez 456 soignants d'un centre hospitalier universitaire, Archives des maladies professionnelles et de médecine du travail, 64(2), 2003, 70-76.

[34] G Mark ans A. Smith, Occupational stress, job characteristics, coping, and the mental health of nurses, British journal of health psychology, 17(3), 2012, 505-521.

[35] G Cresson and N. Gadrey, Entre famille et métier: le travail du care, Nouvelles questions féministes, 23(3), 2004, 26-41.

[36] E Cloutier, H. David, L. Ledoux, M. Bourdouxhe, C. Teiger, I. Gagnon and F. Ouelette, Importance de l'organisation du travail comme soutien aux stratégies protectrices des auxiliaires familiales et sociales et des infirmières des services de soins et de maintien à domicile, IRSST-rapport R-429, 2005, 1-266.

[37] V Sadock, L'enjolivement de la réalité, une défense féminine? Étude auprès des auxiliaires puéricultrices. Travailler, 2, 2003, 93-106.

[38] J.L. Danan, M. Boulangé, H. Coudane and G. Kanny, De la nécessité d'innover à l'émergence de pratiques innovantes en santé, HEGEL, 4(3), 2014, 279-286.

[39] J Smith, Innovation technologique dans les soins de santé. Rapport du comité permanent de la santé, 2013. 